\title{
PRIRODA URBANE TRANSFORMACIJE I MOGUĆNOSTI ZA NJENO OBLIKOVANJE U ODNOSU NA MIGRACIJE KAO IZAZOV
}

\author{
Svetlana Stanarević ${ }^{1}$, Goran J. Mandić ${ }^{2}$, \\ UDK=351.85:711.426]:314.7 \\ Slobodan Spasić $\dot{c}^{3} \quad$ https://doi.org/10.18485/fb_ubur.2018.1.ch11 \\ ${ }^{1}$ Fakultet bezbednosti, Univerzitet u Beogradu, stanarevic@fb.bg.ac.rs \\ ${ }^{2}$ Fakultet bezbednosti, Univerzitet u Beogradu, goran.mandic@fb.bg.ac.rs \\ ${ }^{3}$ Međunarodna bezbednosna asocijacija, Beograd, slobodan.spasic71@gmail.com
}

\section{Sažetak}

Transformacija je proces koji podrazumeva kontinuirane promene tokom vremena i, kao takav, može se vezivati i za prostore kao što su gradovi. Sadašnja urbana struktura, u bilo kojem delu sveta, rezultat je sukcesivnog, tj. uzastopnog dolaska generacija doseljenika koji su napuštali neke fizičke strukture, a naseljavali drugu, kao i delovanja političkih, ekonomskih i društvenih institucija. Otkada je gradova i uređenog urbanog prostora, periodično je dolazilo do urbane transformacije, pa to i nije nov fenomen, već predstavlja određeni način života koji se usklađuje sa vremenom i prostorom.

Više je činilaca koji doprinose transformaciji, ali se smatra da je u poslednjih nekoliko decenija globalizacija presudni. Naime, poznato nam je da globalizacija nije iznenadni događaj ili pojava - to je fenomen koji podrazumeva povezanost ekonomskih, socijalnih, političkih, kulturnih i ekoloških procesa koji neprekidno oblikuju i preoblikuju svet. Globalizacija je ujedno i asimetričan proces, jer se ne odvija geografski ravnomerno, pa, između ostalog, tu asimetriju zapažamo i u većem uticaju na urbane prostore nego ruralne (Mc Grew, 2000). Za neke grupe ljudi ovaj proces je doneo homogenizaciju, dok je za druge proizveo različitost i heterogenost. Za neke je ova globalna pojava smanjila sposobnost pojedinca, porodice ili zajednice da oblikuju sopstvene živote, dok je za druge otvorila mogućnost da te sposobnosti razviju.

Sa globalizacijom su usko povezani i industrijalizacija, tehnološka revolucija, modernizacija, demografski razvoj i, konačno, migracije, koje su kao činilac transformacije konstantno na delu tokom čitave čovekove istorije. Pitanje je kako ovaj činilac deluje u uslovima globalizacije, modernizacije ili tehnološke revolucije i koji je adekvatan odgovor kada migracije i talasi izbeglica zauzimaju gradove i urbane prostore, naruše društvenu koheziju, izazovu negativne reakcije domaćeg stanovništva, utiču na politike na svim nivoima koje se donose u ovoj oblasti itsl.

Uzimajući sve navedeno u obzir, u ovom radu ćemo urbanu transformaciju posmatrati i analizirati iz ugla dva koncepta: jedan je novi urbanizam, a drugi je bezbednosna kultura. Naime, i jedan i drugi koncept primenjuju kulturnu analizu, koja nastoji da unapredi znanje o tome kako određene strukturne promene utiču na društveno okruženje, društveni i kultur- 
ni život grada, a naročito na rastuću društvenu polarizaciju i segregaciju. I ovde ćemo naglasiti značaj kulture društva u celini, koja se ne koristi samo kao sredstvo da se razumeju stvarne promene, već jednako često služi kao sredstvo za proizvođenje promena, što je prepoznatljivo u oba navedena koncepta.

Ključne reči: urbana transformacija, novi urbanizam, bezbednosna kultura, migracije

\section{Uvod}

Transformacije, ili preobličavanja, dešavaju se svuda - dakle, u globalnim ekonomskim, političkim i društvenim strukturama sa projekcijom nadole, približavajući se načinu na koji ljudi oblikuju svoj svakodnevni život. Ovaj koncept u društvenim naukama podrazumeva promene koje se odvijaju na nivou države i/ili društva, a mogu biti tehnološke, ekonomske, političke, institucionalne, pravne i kulturne prirode. Cilj urbane transformacije je da se poboljša socijalni, ekonomski i prostorni kvalitet života gradova, a samim tim i ljudi koji žive ili privremeno borave u tim gradovima. Savremeni gradovi predstavljaju najjače ,ekonomske motore" u svetu, a pretpostavlja se da će transformacija gradova u skladu sa održivim ekonomskim razvojem biti od ključnog značaja za većinu država u 21. veku.

Istraživanja prirode gradske transformacije zahtevala su i razmatranje onoga šta predstavlja grad, s obzirom na njegov višedimenzionalni karakter. Luis Mamford je grad definisao kao ,geografski pleksus, ekonomsku organizaciju, institucionalni proces, pozorište za društvenu akciju i simbol kolektivnog jedinstva“" (Mumford, 2010). Većina definicija grada uključuje neki koncept veličine, pa se grad može prikazati i kao „koncentracija velikog broja ljudi“ (Davis, 1973: 1), „mesta gde veliki broj ljudi živi i radi“ (Saunders, 1986: 7) ili kao „posebne ljudske institucije" (Elliot and McCrone, 1982: 5); dakle, ne samo kao mesto okupljanja velikog broja ljudi, već i centar političkih i pravnih lica/institucija, lokalne samouprave i privredne delatnosti, oblast zabave i rekreativnih aktivnosti. Upravo ideje veličine i kompleksnog skupa institucija pružaju polaznu tačku i za ispitivanje pojma urbane transformacije.

Transformacija podrazumeva promene tokom vremena i, prema tome, procenu važnosti istorijske perspektive razvoja svakog grada. Sadašnja urbana struktura proizlazi iz više tragova koje su ostavile generacije naseljenika u fizičkoj strukturi, ali i u političkim, ekonomskim i društvenim institucijama. Kao i pri saglédanju drugih fenomena, da bi se razumela sadašnjost, neophodna je istorijska perspektiva razvoja uopšte, a onda i razvoja grada. Od prvih stalnih naselja u ljudskoj istoriji do danas gradovi su prošli kroz niz transformacija. Pojavljuju se oko 3.000 do 4.000 godina pre nove ere u dolini Nila i Mesopotamije (Carter, 1983).

Gradovi su isprva nastajali kao mesta trgovine i upravljanja, te, kao takvi, ostali značajni i u svim ostalim periodima. Mnogi gradovi su bili gradovi-države, imali su značajnu ekonomsku i političku moć vekovima, pre nego što su nacije odnosno države postale dominantni geopolitički entiteti. Glavna transformacija se zbila u 19. veku, kroz oblik modernog industrijskog grada, pri čemu su i industri- 
jalizacija i urbanizacija uspostavljale novi, savremeni svet sa industrijalizovanim gradovima koji su brzo rasli i pružali oštro diferencirane rezidencijalne lokacije za nove radnike i nove šefove (Veber, 1889; prema: Thorns, 2002).

Urbanizacija je podrazumevala i velika kretanja ljudi, iz ruralne sredine u gradsku/urbanu, a otkriće Novog sveta, uz propratne migracije, doprinelo je promenama u raspodeli stanovništva i značajan uticaj na rast gradova u pojedinim delovima sveta. Gradovi poput Njujorka bili su naselja migranata, dakle ljudi koje su privukli nova zemlja i mogućnosti koje im se pružaju u odnosu na glad, rat i siromaštvo koje ih je pokrenulo iz njihovih postojbina. Prelazak u industrijski urbani svet 18. i 19. veka proizveo je jednu od velikih transformacija u ljudskoj istoriji odvojeni su rad i stanovanje, a počela je fabrička proizvodnja. Samim tim se menjala urbana struktura mnogih gradova. Dok se priroda urbanog života ranije zasnivala na obimnoj robnoj proizvodnji za ciljano masovno tržište, danas je urbana transformacija prešla na takozvanu industriju znanja i informacija, odnosno nov sistem, zasnovan na stvaranju bogatstva od informacionih usluga koje su globalno organizovane.

Urbana transformacija je danas dovela do gotovo beskonačnog prostranstva izuzetno raznolikih pojmova određenih geografskim, kulturnim i individualnim preferencijama. Hvatanje ukoštac s ozbiljnim razmatranjem o tome šta je ,urbano" podrazumeva detaljno saglédanje ovog pojma u svim njegovim maskiranjima, gradacijama i transformacijama, koje se u isto vreme zbivaju i na globalnom nivou. Gradovi se danas posmatraju kao glavne arene ljudskog postojanja, ne samo zato što tu živi najveći deo svetske populacije, već i zato što je grad jedini oblik prostorne organizacije sposoban da prihvati najveći broj ljudi na Zemlji na održiv način.

Kao što su vidne promene i transformacije vezane za grad i njegovu strukturu, sadržaj, namenu, pa i simboliku, na sličan način su se dešavale i promene kod onog stanovništva koje se kreće i koje ciljano dolazi u gradove i ostala urbanizovana naselja sa namerom da se privremeno ili stalno nastani.

Smatra se da postoje dva glavna modela migracija i njihove inkorporacije koja dominiraju u političkim i akademskim pristupima ovoj temi u drugoj polovini XX veka: prvo, model naseljenika, prema kojem su se imigranti postepeno integrisali u ekonomske i društvene odnose, ponovo ujedinili ili formirali porodice, i na kraju se asimilovali u društvo zemlje domaćina; i, drugo, model privremene migracije, prema kojem su radne migracije podrazumevale boravak u zemlji domaćinu u ograničenom periodu, istovremeno zadržavajući svoju pripadnost zemlji porekla (Thorns, 2002). Globalizacija, kao proces sa prekograničnim tokovima i transnacionalnim mrežama, promenila je kontekst za migracije. ${ }^{1}$ Komunikacija pomoću no-

\footnotetext{
1 Naime, poznato je da globalizacija nije iznenadan događaj ili pojava, nego fenomen koji podrazumeva povezanost ekonomskih, socijalnih, političkih, kulturnih i ekoloških procesa koji neprekidno oblikuju i preoblikuju svet. Globalizacija je i asimetričan proces, jer se ne odvija geografski ravnomerno, pa, između ostalog, tu asimetriju uočavamo i u većem uticaju na urbane prostore nego ruralne (Mc Grew, 2005). Za neke grupe ljudi ovaj proces je doneo homogenizaciju, dok je za druge proizveo različitost i heterogenost. Za neke autore je ova globalna pojava smanjila sposobnost pojedinca, porodice ili zajednice da oblikuju ljudske živote, dok je za druge otvorila mogućnost da te sposobnosti razviju.
} 
vih tehnologija i različite varijante transporta omogućile su česte i višestruke tokove ljudi, ideja i kulturnih simbola. „Erozija državnog suvereniteta $i$ autonomije oslabila je sistem granične kontrole $i$ asimilacije migranata. Rezultat je transformacija materijalnih $i$ kulturnih praksi povezanih sa migracijama i formiranjem zajednica, kao i zamagljivanjem granica između različitih kategorija migranata." (Thorns, 2002: 6)

Ovim tekstom želimo da prikažemo upravo preispitivanje razumevanja migracionog procesa, razumevanja oblika mobilnosti i inkorporacije, posebno u odnosu na pojavu transnacionalnih zajednica, višestrukih identiteta i višeslojnog državljanstva, obuhvatajući sve te fenomene iz ugla dva koncepta - novog urbanizma i bezbednosne kulture. Naime, priroda urbane transformacije se može, ali i mora razmatrati sa aspekta socijalnih i kulturnih promena koje nastaju usled te transformacije ili proizvode tu transformaciju - dakle, kao jedan uzajaman proces, tokom kojeg urbano planiranje uključuje i aspekt sigurnosti i bezbednosti, primenjujući se i na pristup migracijama kao izazovu.

\section{Transformacija gradova i migracije}

Prema već poznatim definicijama, međunarodne migracije podrazumevaju prelazak ljudi preko državnih/nacionalnih granica i u nekim ranijim vremenima pretpostavljalo se da se migranti trajno sele iz jedne države u drugu (trajna migracija stanovništva) ili da će se nakon izvesnog vremena (privremena radna migracija) vratiti kući. U oba slučaja suverenitet i snaga nacije-države nisu dovedeni u pitanje, međutim, u uslovima globalizacije takva očekivanja gube svoju validnost. Migracije postaju sve brojnije, a migranti sve raznovrsniji po socijalnim i kulturnim karakteristikama.

Države se trude da podstaknu određene vrste (kvalifikovane i preduzetničke migracije) i zaustave ili onemoguće druge (nekvalifikovane radne migrante i tražioce azila), ali je teško načiniti jasne razlike i primenjivati utvrđena pravila. Naime, novi razvoj u informacionoj i transportnoj tehnologiji povećavaju obim privremenih, ponovljenih i cirkulatornih migracija. Sve više migranata usmerava svoje živote u dva ili više društava te razvija transnacionalne zajednice i svest (Larrain, 1993; Portes, 1995; Levitt, 1999; Tsakiri 2005).

Takvi trendovi su povezani sa povećanjem snage neformalnih mreža kao načina komunikacije i organizacije koja prevazilazi formiranje nacionalne granice. To može podrivati državne politike u odnosu na kontrolu i smanjenje efikasnosti tradicionalnih načina uključivanja migranata u društvo. Savremene međunarodne migracije odlično se uklapaju u logiku globalizacije, te će strategije kontrole zasnovane na starijoj, nacionalnoj logici verovatno propasti. Tomas Fejst smatra da su migranti u određenom smislu uvek pomerali „transnacionalni društveni prostor“, ali u uslovima globalizacije to za njih postaje sve lakše (Faist, 2000). Ovo se smatra ujedno kontekstom za razumevanje i budućih događaja. 
Ima mnogih razloga koji ukazuju na to da će međunarodne migracije rasti u narednim godinama i da države, ali i međunarodna zajednica, teško da će postaviti neka ograničenja u tom pogledu. Stoga je zanimljivo utvrditi kako će se umnožavanje migracija $\mathrm{i}$ formiranje transnacionalnih zajednica odraziti na društvene odnose, kulture, identitete i politike u zemljama prijema (domaćina) i na politike u urbanim sredinama, gde je koncentracija tih zajednica i najveća. ${ }^{1}$

Osnovna karakteristika nacionalne države koja se razvijala u Zapadnoj Evropi i Severnoj Americi bila je njena pretenzija da će upravljati etničkim razlikama kroz sistem granične kontrole, kao i kroz proces kulturne homogenizacije, ili podređivanja manjine. Kada je u pitanju kontrola granica, ona se pokazala kao prilično nesigurna, pa su, s tim u vezi, države morale da razmišljaju o politikama uključivanja i integrisanja manjina i upravljanja različitošću. Kao što je već naglašeno, globalizacija je dovela do velikih promena u karakteru međunarodnih migracija, tako da se i kontekst za uključivanje ili integrisanje migranata radikalno promenio, a taj trend će se i dalje nastaviti.

Koncept multikulturalizma je bio deo odgovara na ove promene, ali novi oblici identiteta i pripadnosti prevazilaze i taj koncept i politike koje su se razvijale na osnovu njega. Naime, povećanje mobilnosti, rast privremenih, cikličnih i ponavljajućih migracija, jeftino i lako putovanje, kao i konstantna komunikacija kroz nove informacione tehnologije, dovode u pitanje ideju osobe koja pripada samo jednoj državi ili migrira iz jedne države u drugu (bilo privremeno ili trajno). Ove promene dovele su i do rasprava o značaju transnacionalizma i transnacionalnih zajednica ${ }^{2}$ kao novih vidova pripadnosti migranata.

Kakav je odgovor novog urbanizma i bezbednosne kulture na ove izazove, odnosno kako se primenom ovih pristupa mogu tumačiti kompleksnost i kontradiktornost transnacionalnih identiteta a da se ne dođe do inherentne tenzije koja već postoji u transnacionalnoj teoriji? Naime, prikazivanje ili predstavljanje transmigranata može se odvijati na više načina. Ponekad se prezentuju kao kosmopolite koji mogu prelaziti kulturne granice i izgraditi višestruke ili hibridne identitete. Međutim, ima teoretičara koji smatraju da je transnacionalna svest zasnovana pretežno na zajedničkoj etničkoj pripadnosti i pri tome transmigranti osećaju solidarnost sa zajednicama u svojoj domovini čak i kada se nalaze na drugom kraju sveta.

1 Postoji bogata literatura u kojoj se sugeriše da se na listu gradskih problema postave pitanja iskustva migrantskog naseljavanja, integracije i zajednice: studije identiteta migranata (Nack, 2006; Ehrkamp, 2005), izgradnja mesta (Binie et al., 2006; Gill, 2010), razvoj urbanih enklava (Graham and Marvin, 2001), građanstvo i pripadnost (Phillips, 2014) i druga koja otkriva urbanu kontekstualnost života migranata, kao i položaj njihove zajednice i razne pripadnosti.

2 Transnacionalne zajednice su grupe čiji se identiteti ne zasnivaju na vezivanju za određenu teritoriju i zato predstavljaju moćan izazov tradicionalnim idejama pripadnosti naciji. Ove zajednice se trenutno brzo proliferiraju i posledica su procesa globalne integracije. To je delom tehnološko pitanje, ali možda još i više socijalni i kulturni problem, pri čemu se globalizacija vidi kao usko povezana sa promenama u društvenim strukturama i odnosima, kao i promenama u kulturnim vrednostima koje se tiču mesta, mobilnosti i pripadnosti. Na ovo su ukazivali brojni autori (Bauman, 1998; Castells, 1996) koji ujedno smatraju da će transnacionalne veze i svest postati dominantni oblik migranata koji pripada budućnosti, što sve može imati dalekosežne posledice. 
U pravom smislu reči kosmopolite su oni koji se svuda osećaju kao kod kuće i tu uglavnom spadaju pripadnici globalnog biznisa ili profesionalne elite.

Postoje i „,nacije bez države“, zasnovane na prinudnoj rasprostranjenosti pripadnika koji se politički mobilišu i stvaraju ili transformišu svoju domovinu. Većina članova transnacionalne zajednice ipak se nalazi između ovih ekstrema i verovatno ima kontradiktorne i fluktuirajuće identitete. Duga tradicija usmene istorije, ali i brojna literatura o migrantima, pokazale su kako migranti moraju pregovarati o svojim načinima ispoljavanja identiteta, pored inače složenih izbora: povratka, asimilacije i formiranja zajednice. To nisu ekskluzivne opcije, a pojedinci i grupe pronalaze kreativne načine istovremenog prilagođavanja i promene sopstvenog društvenog okruženja, pri čemu se razvijaju odnosi koji pozivaju na otvorenu društvenu akciju, ali i na strategije za svakodnevni život.

\section{Novi urbanizam}

Novi urbanizam je paradigma koja doživljava uspon poslednjih decenija, a predstavlja glavni referentni okvir za saglédanje socijalnih i kulturnih aspekata u urbanom planiranju, kao i povezivanje pristupa iz oblasti urbanističkog planiranja, $s$ jedne strane, i oblasti društveno-humanističkih nauka, s druge strane. Kao urbanistički pokret, ${ }^{1}$ novi urbanizam je nastao u SAD, a pristalice i zastupnici ovog pristupa tvrde da pravilan dizajn prostora dovodi do razvoja lokalne zajednice. „Kroz sveobuhvatni urbani dizajn i planiranje, novi urbanizam nastoji da neguje identitet mesta, osećaj zajednice i održivost životne sredine." (Day, 2003: 83) Novi urbanizam, i kroz teoriju i kroz principe koje promoviše, nije iskrsao preko noći, niti se razvijao iz neproverenih i nedokazanih praksi. Naime, novi urbanizam, kao što je i njegov naziv namenjen da izrazi priključivanje, uzima najbolji istorijski urbanizam i sintetizuje ga novim idejama kako bi izgradio novi smisao urbanizma.

Osnovna ideja novog urbanizma jeste poimanje susedstva kao građevinskog bloka zdravih gradova i naselja. Kada je dobro osmišljeno susedstvo, i odrasli i deca mogu bezbedno šetati do obližnjih tržnica, škola ili parkova. Javne ustanove služe kao kontaktne tačke za aktivnosti u zajednici. Širok spektar stambenih opcija omogućava mešavinu porodica različitih veličina, uzrasta, prihoda i kulture da žive skladno. Susedi se poznaju i neguju osećaj zajedništva u svom životnom okruženju, a na svakom koraku se gaji duh zajedništva koji može da pomogne u saniranju nekih problema i ponovnoj izgradnji grada.

1 Pokret novog urbanizma se razvija od 1980-ih. Godine 1993. Andres Duany, Peter Calthorpe i Peter Katz, zajedno sa drugim arhitektama i novinarima, osnovali su tzv. Kongres za novi urbanizam, institucionalizujući razvojni pokret na osnovu 27 pravila/principa predstavljenih u Povelji novog urbanizma, koja je usvojena 1996 (The Charter of the New Urbanism). Od tada se proširio i na druge zemlje, kao što su: Kanada, Australija, ali i mnoge evropske države. Novi urbanistički principi predstavljaju smernice za odnos između delova grada i način na koji oni mogu da funkcionišu zajedno da bi sazdali integrisanu celinu. 
Uvođenje novih urbanističkih pristupa podrazumeva i promovisanje, a potom i poštovanje određenih načela, na koja ukazuju savremeni teoretičari, a koja su proklamovana i u Povelji novog urbanizma. Samo neki od njih glase:

- visoka prohodnost i relativno mešovita upotreba ulica i javnih prostora;

- uključenost građana i zajednice (naglasak na prioritetu ljudske uloge u urbanom dizajnu i planiranju);

- raznolikost/različitost (obezbediti širok spektar tipova stanovanja i nivo cena za ljude različitog uzrasta, rase, prihoda i svakodnevne interakcije, jačanje ličnih i građanskih veza neophodnih za autentičnu zajednicu);

- ispunjeni razvoj (naglasak na revitalizaciji i očuvanju starih tekstura i gradova, kao i obnovu unutrašnjih delova grada koristeći ispunjeni strateški razvoj kako bi se sačuvale ekonomske investicije i socijalna struktura);

- lokalni arhitektonski karakter (imidž i karakter novog razvoja treba da odgovori na najbolje tradicije stambene i mešovite arhitekture u ovoj oblasti; pokušati da se vrati umeće gradogradnje i tradicionalnog planiranja, i biti svestan potreba zajednice [Talen, 1999]);

- podržati bezbednost, sigurnost - kroz građansko angažovanje, odnos zgrada i ulica treba da omogući susedima da stvore bezbedno i stabilno susedstvo obezbeđujući „oči na ulici“ i treba da podstiče interakciju i identitet zajednice. Dizajn ulica i zgrada treba da ojača bezbedno okruženje, ali ne nauštrb pristupačnosti i otvorenosti (Leccese, McCormick, 2000: 133). Ovaj princip se zalaže za stvaranje bezbednih i sigurnih javnih mesta za ljude, ali je teško odrediti šta ljude čini sigurnim i bezbednim. Naime, dok se jedna osoba može osećati sigurno u veoma zatvorenom prostoru, druga osoba se može osećati veoma nelagodno unutar tako strogih granica. „Sigurna mesta ... su uredna, dobro osvetljena i čista. Javni prostori u kojima vidimo ili osećamo druge oko nas čini nas sigurnim." (Leccese, McCormick, 2000: 133)

U skladu sa navedenim principima veoma je važno razvijati sposobnost da se lokalizuju principi novog urbanizma u različitim zajednicama, sa naglaskom na dostupnim praksama, ali i da se koriste savremena tehnološka otkrića, kao što su novi sistemi javnog prevoza: metro i transportni sistemi urbanog stila (Hikichi, 2003). Novi urbanizam ima, dakle, veoma snažnu socijalnu orijentaciju, pa samim tim i humanističku, sa posebnim osvrtom na smisao zajednice. Novi urbanisti jednostavno sugerišu društvenu prirodu ljudskog bića i pretpostavljaju da svako ljudsko biće ima osnovnu društvenu potrebu, ideju koja je inspirisala čuvenog američkog personalističkog psihologa Maslova.

Gradovi su odredišta za većinu svetskih migranata, s obzirom na njihov stepen ekonomske aktivnosti, njihovo kulturno i intelektualno izražavanje te njihov razvoj. Aktuelna globalna diskusija o migracijama i njen efekat prvenstveno su usmereni na nacionalni nivo, sa ograničenom pažnjom posvećenom nivou grada. No, i pored toga, može se reći da gradovi predstavljaju različite kontekste za inkorporaciju migranata. Migranti kroz svoje prisustvo, vidljivost/nevidljivost, društvene 
prakse i institucije pomažu da se preoblikuju gradovi u kojima se oni nalaze u stalnom procesu transformacije (Portes, 2000).

Podsetićemo se da grad, kako je jednom prilikom zapisao znameniti urbani sociolog Robert Ezra Park, predstavlja:

čovekov najdosledniji $i$, u celini uzev, najuspešniji pokušaj da preoblikuje svet $u$ kojem živi u skladu sa svojim željama. Ali, ako grad predstavlja svet koji je čovek stvorio, to je onda svet u kojem je on od tada pa nadalje osuđen da živi. Shodno tome, na indirektan način, $i$ bez ikakve jasne svesti o prirodi svog zadatka, čovek je preoblikovavši grad preoblikovao samog sebe.

Ako je Park u pravu, onda se pitanje o tome kakav grad želimo ne može odvojiti od pitanja kakvi ljudi želimo da budemo, kakve društvene odnose želimo da uspostavimo, kakav odnos prema prirodi negujemo, koji stil svakodnevnog života potenciramo, koje tehnologije smatramo prikladnim, koje estetske vrednosti priželjkujemo. S tim u vezi, Dejvid Harvi (David Harvey) smatra da pravo na grad predstavlja bitno više od prava na individualni pristup resursima. Promena grada zavisi od ostvarivanja kolektivne moći nad procesima urbanizacije i od slobode da se grad preoblikuje kroz preoblikovanje i sebe samih, što čini jedno od zanemarenih ljudskih prava (Harvey, 2008).

Umesto mehanističkog gledanja na gradove, koje je dugo vladalo (gotovo ceo dvadeseti vek), pojavljuje se potreba da se menja programska tačka gledanja i urbanističkog planiranja prema humanističkom novom urbanizmu (Ford, 1999). Različiti gradovi imaju raznolike etničke stilove i stoga raznovrsne zahteve za pravima nad gradom. Ishod toga je da neki gradovi ili delovi gradova kao da stvaraju nešto poput kosmopolitskog senzibiliteta, dok drugi izgledaju kao da su zarobljeni u polarizovanim igrama pokreta i suprotstavljanja koji beskrajno ponavljaju iste stare neskladnosti (Phillips, Robinson, 2015: 5).

Nova urbana agenda iz Kjota (2016) definisala je principe u odnosu na „pravo na grad“, a podržana je Deklaracijom iz Njujorka (2016), koja štiti prava migranata u tom procesu. ${ }^{1}$ Više miliona raseljenih ljudi u poslednjoj migrantskoj krizi 2015/2016. dovelo je u pitanje tradicionalne teorije i prakse urbanističkog planiranja, koje zahtevaju inovativne ideje kako bi se ova migranstka kriza pretvorila u priliku (Murillo, 2017).

1 „Priznajemo da izbeglički kampovi treba da budu izuzetak, $i$, u stepenu u kojem je to moguće, privremena mera, kao odgovor na vanredne situacije. Napominjemo da je 60\% izbeglica širom sveta u urbanim sredinama $i$ da je tek manjina njih u kampovima. Mi ćemo osigurati da se pružanje pomoći, izbeglicama i zajednicama domaćina prilagodi relevantnom kontekstu. Naglašavamo kako države domaćini imaju primarnu odgovornost da osiguraju civilni i humanitarni karakter izbegličkih kampova i naselja. Mi ćemo raditi na tome da ovaj karakter ne bude ugrožen prisustvom ili aktivnostima naoružanih elemenata i da se osigura da se kampovi ne koriste u svrhe koje nisu u skladu sa njihovim civilnim karakterom. Delovaćemo na jačanju bezbednosti u izbegličkim kampovima i okolnim lokalnim zajednicama, uz saglasnost zemlje domaćina." (New York Declaration for Refugees and Migrants, 2016: 13, A/RES/71/1) 
Kao što smo videli, moguće je identifikovati nove pristupe u teritorijalnom planiranju koji reaguju na rapidnu urbanizaciju, što se može shvatiti kao proces društveno-teritorijalne transformacije uzrokovane migracijama i prisilnim raseljavanjem stanovništva. Sada već postoje iskustva stečena razvojem participatornih i samoorganizujućih sredstava za planiranje, koja imaju za cilj merenje ljudskih prava za kreiranje humanitarnih i razvojnih planova, dok uporedne studije daju empirijske dokaze za procenu različitih pristupa planiranju, strategijama i postignućima. Postoji tendencija da se dâ prioritet različitim participativnim planovima, koji se moraju prilagoditi potrebama različitih kategorija migranata i raseljenih grupa, a ne pristupima odozgo nadole, koji ne mogu sprečiti negativne uticaje na najugroženije osobe (Murillo, 2017).

Takođe, predlaže se promena paradigme planiranja kako bismo se udaljili od tradicionalnih odgovora, kao što su izbeglički kampovi ili neformalna naselja koja samo privremeno ugošćuju migrante, ne bi li se stvorili podsticaji za samoorganizovanje zajednice i izgradila infrastruktura koja podržava radna mesta, stvaranje prihoda i raznolika stambena naselja. Ističe se izvodljivost integracije, humanitarnih i razvojnih agendi koje obuhvataju naknadne vrednosti zemljišta koje stvaraju humanitarne investicije. Na ovaj način, reakcije na migracionu krizu doprinose oblikovanju novog plana za višestruki obim koji podržava dugoročne reforme urbane politike u pravcu održivog ispunjenja ljudskih prava.

$\mathrm{Na}$ osnovu razmišljanja koje se uočava u izveštaju UNHCR-a o ,alternativnim kampovima“", predlaže se politika koja se udaljava od izgradnje posebnih naselja za izbeglice i podstiče gradove da ih uključe u sadašnja naselja (UNHCR, 2014). Međutim, da li će ovaj potez dovesti do relevantnih promena u prostornom planiranju, ključno je pitanje oko kojeg se tek otvaraju rasprave. Kao što smo već naveli, u najopštijem smislu, migracioni obrasci uključuju ekonomske migrante i prisilno raseljeno stanovništvo. Obe grupe oblikuju koridore migranata koji stvaraju brzu urbanizaciju u različitim veličinama gradova, tipovima i njihovom zaleđu. To se može primetiti u urbanom širenju, širenju neformalnih naselja, oskudicama u infrastrukturi, povećanju vrednosti zemljišta, kršenju ljudskih prava i rastućoj napetosti između migranata i domaćeg stanovništva sa kojima konkurišu oko osnovnih urbanih usluga.

Neki novi planski pristupi za prijem i ugošćavanje izbeglica i interno raseljena lica, učeći iz iskustva već odomaćenih ekonomskih migranata, pružaju dokaze za istovremenu zaštitu ugroženih nacija i migranata putem okvira pametnih politika. Ovo uključuje vođenje urbanog razvoja, urbanu ekspanziju, programe za izgradnju siromašnih gradskih četvrti, periferna naselja, nove gradove i samoodržive kampove, između ostalih. Komparativna procena ovih pristupa osigurava principe planiranja kako bi se uskladili humanitarni i razvojni programi u različitim kontekstima.

U skladu sa napred rečenim, razvijaju se novi instrumenti participativnog planiranja koji vode inovativnim pristupima planiranju. Način promovisanja ovakvog participativnog planiranja za lokalne vlasti znači uvođenje novih mehanizama kako bi mogli raditi skupa sa raseljenim zajednicama i kako bi odredili i prioritete 
za delovanje. Tako, na primer, ,kompas“ je participativna metodologija koja se koristi za prikupljanje podataka od domaćina i raseljenih zajednica, koristeći ključne pokazatelje za merenje njihovih životnih uslova, izraženih u smislu ljudskih prava, organizacije zajednice, propisâ i tekućih radova (Murillo, 2017).

Ova metodologija ima cilj da proizvede bitne informacije potvrđene od strane zajednica sa niskim prihodima, uključujući stanovnike slamova koji obuhvataju ugrožene domaće stanovništvo i migrante. Ona okuplja zajednice i lokalne vlasti kako bi žitelji razgovarali o prioritetima i odabrali akcione planove. Velika prednost ove metodologije sastoji se u tome što izražava rezultate participativne dijagnoze i dogovorene predloge, odražavajući prednosti i slabosti alternativnih pristupa planiranju da bi se odgovorilo na izazove brze urbanizacije. Prema tome, mogu se predložiti i novi principi planiranja koji uvažavaju integrisanje humanitarnih i razvojnih planova, kakvi se donose na osnovu kooperativnih strategija između više aktera. U okviru dokumenta koji je proistekao nakon sastanka ekspertske grupe za održive gradove, ljudsku mobilnost i međunarodne migracije u okviru UN, 2017. godine, postavljeno je pitanje da li migracije i ubrzana urbanizacija doprinose postavljanju nove agende za humanitarno i razvojno urbano planiranje, gde su predloženi i sledeći principi:

- Participacija, samoorganizovanje i progresivno unapređenje migranata, izbeglica i interno raseljenih lica - u ovom slučaju planeri rade zajedno sa migrantskim zajednicama, čime se, poštujući želje i mogućnosti uključenih zajednica, vraćaju ljudsko samopoštovanje i vrednost zajednicama da upravljaju svojom budućnošću, a ne samo da budu primaoci pomoći. Kao referentni model, u literaturi se navodi grad Medeljin u Kolumbiji, koji je inače primio veliki broj izbeglica iz Venecuele.

- Humanitarna ulaganja koja se kanališu u infrastrukturno proširenje umesto da se izbegličke i migrantske zajednice vođene potrebama preživljavanja samoorganizuju i mobilišu svoje finansijske i ljudske resurse, lokalni urbanisti koriste humanitarna sredstva za proširenje infrastrukture, što može imati ključnu ulogu u povezivanju ovih zajednica i lokalne vlasti odabiranjem strateških područja za obnovu. Primer je Kigali, glavni grad Ruande.

- Izgradnja povoljnog tržišta za iznajmljivanje u sadašnjim urbanim područjima - samoizgradnja daje raseljenim porodicama šansu da organizuju stanište na fleksibilan način, pri čemu se stvaraju različite vrste prelaznih skloništa koja postepeno postaju trajni smeštaj. Tako, na primer, naftne kompanije zahtevaju pristupačne stanove za smeštaj svojih zaposlenih, ali i dostupnost hotela i stanova za iznajmljivanje kao strategiju za smeštaj zaposlenih umesto radničkih kampova. Međusobni sporazumi između ovih kompanija i lokalnih vlasti dozvoljavaju da se ovaj stambeni fond prenese nakon perioda lizinga, kada migrant više nisu potrebni (obično nakon 5 godina). 
- Povećanje gustine naseljenosti i kombinovano korišćenje zemljišta koje podržava ugrožene grupe. Usaglašavanje urbanističkih regulatornih okvira razvijenih kroz vežbe participativnog planiranja sa izbegličkim grupama koje su prihvatljive lokalnim samoupravama mogu biti ključ za razvoj oblasti u kojima korišćenje mešovitog zemljišta i povećanje gustine stvara različite pristupačne obrasce stanovanja prema prihodima i preferencijama stanovnika (primer: pojas Gaze - Plan za ponovni smeštaj izbeglica UNRWA).

- Stvaranje novih radnih mesta, dohodak i održiva lokalna tržišta - kroz uvođenje osnovnih socijalnih usluga, kao što su zdravstvene i obrazovne ustanove i centri u zajednici, kako bi se izgradilo poverenje ugroženih grupa i kako bi se pružila podrška ostvarivanju njihovih prava, što je uslov za njihovu stvarnu integraciju. Postoje primeri gde se izbeglicama nude poslovi u industrijskim parkovima, što je u skladu sa humanitarnim i razvojnim strategijama (Čile); ili ponuda da nakon dugogodišnjeg izbeglištva postanu građani države gde su se nastanili, odnosno da im se daju zemljište i podrška u pograničnom području kao deo nacionalne politike države koja ima ogromnu teritoriju a malu populaciju (Zambija).

- Strategija regionalnog razvoja - uz adekvatnu gustinu i dovoljno raspoloživog prostora, raseljene zajednice mogu otvoriti male trgovine i skladišta kako bi ostvarile osnovni prihod. Na globalnom jugu neformalna naselja često obezbeđuju kvalifikovane građevinske radnike, a u pojedinim slučajevima migrantske zajednice uzgajaju voće i povrće na perifernim područjima. UN HABITAT i UNHCR grade periferna naselja za produktivne IRL, pri čemu kombinuju lokaciju, usluge i samostalno izgrađene stambene objekte, plus male poljoprivredne programe koji stvaraju dohodak i dobrobit u gradovima (Darfur - Sudan).

- Koordinirane aktivnosti javnosti i zajednice na više nivoa - ovaj princip je ključan za pravilno postupanje sa migrantskim i raseljenim stanovništvom, jer uključuje regionalnu dimenziju, koja utiče na čitav sistem gradova. Stvaranje faktora privlačenja ${ }^{1}$ u strateškim gradovima za naseljavanje raseljenih lica sa ciljem povratka u svoja mesta porekla, ključno je za minimizovanje negativnih posledica raseljavanja u okviru socijalne zaštite (Južni Sudan).

$\mathrm{U}$ celini gledano, migracione politike mogu uticati na gradove na pozitivan i negativan način. Restriktivne, neadekvatne ili nejasne politike u pogledu mobilnosti radne snage mogu ohrabriti neregularne migracije i rast neformalnih gradskih naselja (IOM, 2015: 117). Takođe, stroge politike granične kontrole mogu stvoriti gradska tranzitna čvorišta gde migranti ostaju zaustavljeni na putu prema željenim

1 Planeri u Južnom Sudanu svojevremeno su se složili da stvaraju nova naselja i gradove sa nacionalnom strategijom reintegracije povratnika koja će podsticati uravnoteženu distribuciju stanovništva. Strategija je zasnovana na tri stuba: projekti brzog uticaja (škole, putevi i voda/kanalizacija); lokacije, servisi i skloništa; kao i planovi za stvaranje prihoda. Sukobi koji su se nastavili na ovom području, na žalost, doveli su do propasti ovih dostignuća. 
destinacijama. Da bi se poboljšale politike lokalnih vlasti, potrebno je bolje razumeti savremene migracije, izazove i metode uključivanja zajednica migranata sa domaćim stanovništvom, ali i ukazati pažnju sledećim činjenicama: da li se govori o stalnim ili privremenim migracijama (one se često doživljavaju kao trajne, što rezultuje restriktivnim politikama, a zapravo istraživanja pokazuju da je većina migracija u gradovima privremena i ciklična); migracija u novu zemlju ili grad višestepen je proces (integracija zavisi od više faktora, uključujući poznavanje lokalnog jezika, dostupnost radnih mesta, pravni status, učešće u građanskom i političkom životu i pristup socijalnim uslugama); od ključnog značaja je i osiguranje zastupljenosti $i$ uključivanje migranata u proces donošenja odluka; ranjivost na urbano nasilje i kriminal (migranti su podložniji urbanom nasilju i kriminalu, uključujući trgovinu ljudima, radnu eksploataciju, lažne dokumente, neregularno stanovanje, nelegalne usluge, neregularne agencije za zapošljavanje i korumpirana policija). Da bi se raspolagalo adekvatnim znanjima o samom procesu migracija i kako odgovoriti na njih, o tome kako preporučiti bezbednost kao važnu referencu urbanog planiranja i dizajna i kako doprineti bezbolnim urbanim transformacijama, potrebno je uvesti u izlaganje i koncept bezbednosne kulture.

\section{Bezbednosna kultura}

Više je razloga zašto je važno primeniti i koncept bezbednosne kulture prilikom urbanističkog planiranja kako bi se i proces transformacije odvijao što bezbolnije. Naime, kultura određuje ponašanje i percepciju ljudi te definiše ono što predstavlja subjektivnu bezbednost, zatim, okvir za urbanizam se u izvesnoj meri određuje kulturološki i, konačno, kulturno ponašanje se orijentiše prema okruženju, odnosno rezultat je urbanističkog planiranja (Siedschlag et al., 2012). S tim u vezi, bezbednosna kultura bi podrazumevala takve aktivnosti i ponašanja u nekoj (ne)bezbednosnoj situaciji, koji proističu iz odgovornosti i spremnosti delovanja svih subjekata/aktera u jednom društvu, u skladu sa stečnim znanjima i veštinama, kao i prihvaćenim vrednostima i vrednosnim orijentacijama, verovanjima i izgrađenim stavovima utemeljenim u datoj kulturi i kulturnom nasleđu. Ogleda se u načinu na koji se najšire shvata okruženje, ispoljava razumevanje za dinamiku društvenih odnosa (i na pojedinačnom i na širem planu), uočava važnost apsolutne kontrole nad sopstvenim dobrima, načina na koji se uočavaju i definišu opasnosti/pretnje, zatim određuju interesi i biraju sredstva ili instrumenti za delovanje (Stanarević, 2012). Tokom procesa urbane transformacije, cilj primene bezbednosne kulture bi bio da osmisli, pripremi i omogući ostvarivanje bezbednosti pojedinca, zajednice i svakog organizovanog ljudskog entiteta, da se ne desi bezbednosna katastrofa, kao najviše i najrestriktivnije ostvarenje bezbednosne pretnje, $\mathrm{s}$ jedne strane, a da se svi akteri i/ili članovi zajednice osposobe da koriste sve svoje mogućnosti za razvoj i napredak, s druge strane.

Kao i novi urbanizam, i bezbednosna kultura koristi pristup bezbednosti u zajednici. On podrazumeva zaokret u razvoju infrastrukture, političkog i javnog shvatanja bezbednosti, od situacione prevencije do bezbednosti zajednice u celini. To zahteva i poseban senzibilitet za multikulturalno planiranje, u sredinama gde je ta multikulturalnost već izražena ili u sredinama gde postoji mogućnost da se multikulturalnost tek razvije, što može biti rezultat novih migracionih tokova i naseljavanja ili privremenog prisustva/bo-ravka migranata u urbanom gradskom prostoru (Baum, 2000: 115).

Različiti činioci doprinose tome da su urbane sredine veoma ranjive. Polovina svetskog stanovništva trenutno živi u urbanim centrima, te su pitanja bezbednosti i sigurnosti građana od najvećeg značaja i izazivaju sve veću zabrinutost. 
U iskazima vezanim za bezbednost kultura se često koristi kao imenitelj za svakodnevne životne uslove, kao i uslove socijalne isključenosti unutar/izvan grupne formacije. Tako je u kriminološkim istraživanjima utvrđeno nekoliko kulturnih (socioloških) faktora u vezi sa pojavom kriminala i rizikom od kriminala (stvarna pretnja):

- kulturne norme koje definišu muškost i deluju kao sredstvo za ostvarivanje nasilja od strane marginalizovanih mladih muškaraca, koji se osećaju isključenim iz normalnih načina donošenja rodno specifičnih normi kako bi pokazali muškost;

- kulturne norme koje definišu muškost i dehumanizuju ljude, koji proizla-ze iz dominantne kulture normalnosti (npr. nasilje nad homoseksualnim muškarcima);

- politička kultura koja pruža plodno tlo za zločine iz mržnje protiv ljudi koji predstavljaju drugost;

- ideološke konstrukcije društvenih sistema (kao što je porodica) koje uključuju osećaj prava - čak i nasilne - kontrole muškaraca nad ženama;

- kulturne norme prihvatljivog nasilja, primera radi, u sportu, školama i zabavi, koje, međutim, mogu izazvati i višak nasilja (prekomerno nasi-lje) (White/Habibis 2004: 67-68).

Međutim, različite percepcije i spor oko rizika i bezbednosti može da bude povezan sa konkurentskim pogledom na svet, što je najvažnije u multikulturnim gradovima, gde koncepti rizika, bezbednosti i rešenja za bezbednosne probleme zavise od organizacije političkih i društvenih odnosa. Rizici i pretnje bezbednosti izabrani su kao važni jer pojačavaju utvrđene interpretacije i odnose u kulturi, čime reprodukuju simboličke temelje zajednice: ,zajedničke vrednosti dovode do zajedničkih strahova [...]. Ne postoji jaz između percepcije i stvarnosti.“ (Douglas, M. Wildavsky 1982: 8)

Kao što je već pomenuto, opšta pretpostavka kulturoloških pristupa u percepciji (ne)bezbednosti jeste da kategorije kao što je strah od kriminala zavise od kulturno ugrađenih značenja rizika. Tako, na primer, imigrantske kulture mogu da se tumače kao uzrok socijalnoj radikalizaciji, koja može porasti do pretnje za unutrašnju bezbednost; bezbednosna kultura nekoga ko koristi savremenu IT tehnologiju može da se tumači kao društveno zaštitni zid/brana protiv IT bezbednosnih dela itsl. Čim se uoči kontinuirano uključivanje bezbednosnih pitanja i aspekata u urbano planiranje i projektovanje, znači da je bezbednosna kultura kao koncept i kao praksa/rutina u potpunost prihvaćena ili ustaljena. Mnoštvo je primera gde se to može ilustrovati.

Postoje lokacije urbanog prostora koje su znatno atraktivnije i podesnije za činjenje nekog krivičnog dela (terorizma, na primer), i to upravo iz socijalnih $\mathrm{i}$ kulturnih razloga. Odgovarajućim oblikom izgrađene insfrastrukture mogu se smanjiti rizici, zaštititi prometna javna mesta ili prostori, primeniti zaštitne mere bezbednosti i visok kvalitet urbanog dizajna itsl. Za razliku od koncepta projektovanja infrastrukture koji poštuje principe bezbednosti i samim tim predstavlja osnovni instrument za ublažavanje bezbednosnih rizika, postoje i inkluzivni koncepti, kao što je „podsticajno planiranje“, ${ }^{1}$ koje ima težište na sveobuhvatnom participativnom planiranju (naročito pogodno za multikulturalno gradsko okruženje).

1 Podsticajno planiranje je metoda usmerena na zajednicu radi učešća građana u urbanom planiranju (učešće javnosti ili konsultacije). Koristi se za prikupljanje informacija od određenih ključnih aktera, kako bi se izradila zajednička vizija budućeg grada, uključujući politike planiranja, strateške 
Koncept „podsticajnog planiranja“ zasnovan je na uzajamnom poštovanju, poverenju i akciji zasnovanoj na zaštiti. To je ujedno i dvosmerno učenje i pristup planiranju kroz rešavanje problema. Ovaj koncept objedinjava racionalne i iracionalne procese društvene interakcije i društvenog učenja koji će građanima i stručnjacima omogućiti da zajednički rade na rešavanju problema i donošenju odluka na dobrobit svojih zajednica. Na taj način omogućava planerima da cene vrednu imovinu koje multikulturne grupe donose gradskom životu i planiranju rasprave" (Ameyaw, 2000: 101). Cilj primene ovog koncepta je da stvori kontekst u kojem planer i multikulturne grupe kontinuirano uče i eksperimentišu, misle sistematski, uključuju u smislen dijalog i stvaraju vizije energičnijih akcija i uključivanja u urbanizam i urbanističko planiranje.

Sledeći primer uključivanja bezbednosne kulture u urbane studije može biti i pristup bezbednosti zajednice. Ovde je važno naglasiti značaj zajednice koja je, pre svega, zasnovana na poverenju, tj. očekivanju jednih članova zajednice da će se drugi članovi te zajednice ponašati regularno, pošteno i kooperativno, zahvaljujući tome što dele zajedničke norme, koje se mogu odnositi i na kodove ponašanja ili standarde u određenom (urbanom) kontekstu (Stanarević, 2012). S tim u vezi, na osnovu koncepta bezbednosne kulture, urbanog istraživanja, ali i uvažavajući principe urbanog planiranja, potrebno je posebno razmotriti i sledeće činjenice:

- Upoznati kulturu - upoznati se sa kulturama javne bezbednosti koje utiču na građane, kao i prihvatanje urbanističkih odluka planiranja kakve implementiraju bezbednost u planske odluke.

- Svest o kulturnom značenju - razmotriti uticaj kulture na urbanu strukturu i urbanističkog planiranja na kulturu, imajući u vidu da kulturni aspekti prevazilaze očuvanje istorijskih tvorevina i zaštitu tradicionalnog imidža grada. Kultura je povezana sa dinamičnim društvenim procesima i određuje značenje koje građani pripisuju izgrađenoj urbanoj strukturi. Ovi procesi se ne mogu planirati, a smisao ne može biti samo društveno prenošenje dizajna urbanog prostora.

- Sveobuhvatna analiza rizika - koristiti pristup kulture rizika društva, kako bi se utvrdili aspekti bezbednosti u urbanom planiranju i potrebe za zaštitom koje se mogu zanemariti tehnološkim pristupom analizi rizika.

- Integrisati kulturne komponente otpornosti - razmotriti u planiranju jačanja otpornosti da otpornost i ranjivost prema kojima je to planiranje usmereno uključuju elemente javne/opšte kulture - kao što su moralna i društvena spremnost građana, društvene mreže itsl. Planiranje treba da radi sa tim aspektima - ne preko ili protiv njih. Otpornost kao sposobnost učenja i prilagođavanja promenljivom okruženju suštinski uključuje društvene karakteristike. Ovo obuhvata načine na koje građani percipiraju urbano okruženje i bezbednost, kao i njihova očekivanja od vlasti.

ciljeve i upravljanje razvojem. Učesnici se ohrabruju da vrednuju i ocenjuju prethodna dostignuća u planiranju te da se usredsrede na dalje planske akcije koje smatraju neophodnim. 
Svaka od navedenih činjenica može se staviti u kontekst prisustva migranata u urbanom gradskom prostoru, gde se i oni uključuju kao akteri koji upoznaju kulturu grada gde su se privremeno ili stalno nastanili, ali i dozvoljavaju da drugi nauče o njihovoj kulturi; razvijaju svest o kulturnom značenju urbane strukture za domaće stanovništvo, na osnovu čega je čuvaju i poštuju; doprinose sveobuhvatnoj analizi rizika iznošenjem sopstvene percepcije i integrišu sopstvene kulturne komponente otpornosti.

\section{Zaključak}

Način na koji je preoblikovan grad (iz industrijskog u globalni) u drugoj polovini $\mathrm{XX}$ veka doveo je do možda njegove najveće transformacije. Tradicionalne teorije urbanog planiranja, kao i tradicionalne teorije u polju bezbednosti, dovode se $u$ pitanje, jer ne odgovaraju zahtevima stvarnosti u svakodnevnom životu. Podstiču se novi načini razumevanja složenih globalnih procesa, kao što su urbanizacija i migracije, što nužno zahteva i nove pristupe i inovativna rešenja za probleme koji proističu iz tih procesa. Životni putevi migranata ukrštaju se u gradovima, menjaju ih, a svakodnevnim pokretima, mešanjem i razmenom, takođe, zasićuju i transformišu urbane prostore.

Urbane sredine su sve ranjivije, tome doprinose različiti činioci (pa i migracije), te je iz tog razloga sve važnije prilikom strateškog planiranja uzimati u obzir više elemenata koji će dati jasniju sliku zatečenog stanja i dobru osnovu za kreiranje rešenja, kao odgovor na uočene probleme. Migracije oduvek doprinose transformaciji gradova, što se može sagledati i na pozitivan i na negativan način, a onda naravno se mora uvažiti i aspekt bezbednosti, koji je sve izraženiji i u urban(ističk)im teorijama. Novi urbanizam, sa svojom socio-prostornom perspektivom, ekološkom brigom, planiranjem vrednovanja ili pristupom bezbednosti zajednice, uključuje bezbednosne aspekte u smislu da urbane strukture i dizajn, izgrađeno okruženje i društvo međusobno deluju i utiču jedni na druge. $\mathrm{O}$ ovome bi trebalo više razmišljati prilikom planiranja i uređenja prostora koji se rapidno urbanizuju, usled velikog priliva migranata (naročito kategorije izbeglica i interno raseljenih lica) i može se iskoristiti u svrhu poboljšanja bezbednosti i otpornosti. Zato bi i buduća istraživanja urbane bezbednosti morala da uzmu u obzir pristup urban(ističk)og planiranja koji će doći do krajnjeg korisnika u zajednici.

Urbano istraživanje i planiranje, $s$ jedne strane, $i$ bezbednosna istraživanja i bezbednosne politike, s druge, trebalo bi da se više uzajamno angažuju. Naročito bi trebalo razmotriti aspekte bezbednosne kulture na sveobuhvatan način, a, takođe, pri urbanističkom planiranju koje se bavi kulturom i etičkim aspektima potrebno je više uzeti u obzir subjektivnu (percipiranu) (ne)bezbednost, osećaj ranjivosti i prihvatanje tehnoloških rešenja za bezbednosne probleme.

Dizajn urbanog prostora i infrastrukture utiče na društveno ponašanje i osećanja, te je stoga potrebno uključiti javna značenja, baviti se prihvatanjem građana i njihovog odnosa prema prostoru, kao i osigurati legitimnost odluka o planiranju. 
Dinamičnom procesu u evoluciji otpornih gradova potrebno je aktivno učešće građana, zapravo svih kategorija ljudske populacije koje se mogu naći u određenom prostoru i koji mogu imati specifične potrebe i specifične zahteve za bezbednim boravkom na/u tom prostoru. $\mathrm{O}$ ovome naročito treba voditi računa, jer percepcija rizika građana, između ostalog, određuje njihovo prihvatanje strategija za smanjenja rizika i može rezultovati novim društvenim zahtevima za urbanističko planiranje i bezbednosne misije koje bi bilo poželjno uključiti.

\section{Literatura}

1. Baum, H.S. (2000). "Culture Matters - But It Shouldn't Matter Too Much", in: Burayidi, M.A. (ed): Urban Planning in a Multiculutal Society, Westport, CT: Greenwood, 115-136.

2. Castles, Stephen (2002). "Migration and Community Formation Under Conditions of Globalization," International Migration Review, Vol. 36, No. 4.

3. Castles, Stephen (2001). "Studying Social Transformation." International Political Science Review (Special Issue)Volume 22 issue 1, page(s) 13-32.

4. Castles, Stephen (2001). "Labour Migration, Transnational Communities and States' Strategies in East Asia." Bulletin of the Royal Institute for Inter-Faith Studies, Vol. 3 (2) Autumn/Winter.

5. Davis, K. (1973). Cities: Their Origin, Growth and Human Impact. San Francisco: W.H. Freeman and Company.

6. Elliot, B., and D. Macrone (1982). The City Patterns of Domination and Conflict. London: Macmillan - now Palgrave Macmillan.

7. European project "Mobile Identities: Migration and Integration in Transnational Communities" (HOME/2012/EIFX/CA/CFP/4201) funded by the European Commission, DG Home, within the framework of EIF Fund.

8. Faist, Thomas. (1999). "Transnationalization in International Migration: Implications for the Study of Citizenship and Culture." Institute for Intercultural and International Studies, University of Bremen.

9. Faist, Thomas (2000). The Volume and Dynamics of International Migration and Transnational Social Spaces. Oxford: Oxford University Press.

10. Mamford, L.(2010). Kultura gradova. Novi Sad: Mediterran Publishing.

11. Mc Grew, A (2000). Sustainable Globalization? The Global Politics of Development and Exclusion in the New World Order" in T. Allen and A. Thomas (eds), Poverty and Development into the $21^{\text {st }}$ Century, Oxford University Press, Oxford.

12. Mega, V. (1996). "Our city, our future: towards sustainable development in European cities", Environment and Urbanization, Vol. 8(1), 133-154.

13. Levitt, Peggy (1999). "Towards an Understanding of Transnational Community Forms and Their Impact on Immigrant Incorporation." Paper presented at Comparative Immigration and Integration Program (Winter Workshop) University of California, San Diego.

14. Łucka D. (2018). "How to build a community. New Urbanism and its critics," Urban Development Issues, vol. 59, pp. 17-26.

15. Murillo, Fernando (2017). "Migrants and Rapid Urbanization: A New Agenda for humanitarian and development urban planning? United nations expert group meeting 
on sustainable cities, human mobility and international migration, Population Division Department of Economic and Social Affairs", United Nations, Secretariat New York, 7-8 September 2017.

16. Phillips, Deborah, and Robinson, David (2015). Reflections on migration, community, and place. Population, Space and Place, 21 (5), 409-420.

17. Portes, Alejandro (1995). "Transnational Communities: Their Emergence and Significance in the Contemporary World System." In Proceedings: The Political Economy of the World System: Latin America in the World Economy. The North-South Centre, University of Miami.

18. Rosenau, J. N., and Czempiel, E.-O. (eds.) (1992). Governance without government: Order and change in world politics. Cambridge University Press.

19. Saunders, P. (1986). Social Theory and the Urban Question, (2nd edn). London: Hutchinson.

20. Scholte, J.A. (2000). Globalization: A Critical Introduction. Basingstoke: Macmillan Press - now Palgrave Macmillan.

21. Siedschlag A., Stangl R., Silvestru, D., Fritz F., Jerković, A., Kindl, S. (2012). "Methods to integrate considerations on culture, ethics and citizen acceptance into urban planning for resilience enhancing and vulnerability reduction regarding citizen security." Paper presented at the European Urban Research association Conference, Vienna, Austria.

22. Simmel, G. (1971). On individuality and social forms, edited by D. Levine. University of Chicago Press.

23. Smith, J., Chatfield, C. and Pagnucco, R. (eds.) (1997). Transnational social movements and global politics. Syracuse University Press.

24. Stanarević, S. (2012). Koncept bezbednosne kulture i pretpostavke njegovog razvoja, doktorska disertacija, Fakultet bezbednosti, Univerzitet u Beogradu.

25. Thorns David C. (2002). The Transformation of Cities, Urban Theory and Urban Life, Palgrave Macmiillan, New York.

26. Tsakiri, E. (2005). "Transnational Communities and identity", Refugee Survey Quarterly, Volume 24, Issue 4, pp. 102-104.

27. UNHCR (2014). UNHCR Policy on Alternative to Camps. Available at http://www.unhcr.org/5422b8f09.pdf

28. White, R.(D.), Habibis, D. (2004). Crime and Society. Oxford et al.: Oxford University Press. 


\title{
THE NATURE OF URBAN TRANSFORMATION AND CAPACITIES FOR ITS SHAPING RELATED TO MIGRATIONS AS A CHALLENGE
}

\begin{abstract}
Summary
Transformation is a process which involves continuous change in time and, as such, it can also be associated with spaces like cities. The current urban structure, in any part of the world, results from the successive, i.e. permanent arrival of generations of immigrants who abandoned some physical structures and inhabited others, as well as from the working of political, economic and social institutions. From the initial rise of cities and urban space, there have been, periodically, urban transformations, so that rather than being a novel phenomenon, they represent a certain way of life which is adjusted to time and space. In fact, transformations take place everywhere, in global economic, political and social structures, and project themselves downwards, in the way people organize their everyday life. Urban transformation is aimed at improving the social, economic and spatial quality of life in cities and, by extension, of the inhabitants who live or temporarily reside in these cities. Contemporary cities represent the strongest economic engines in the world, and it is believed that their transformation in line with sustainable economic development will be of key importance to most countries in the $21^{\text {st }}$ century.

There are a number of factors contributing to this transformation, but it is generally considered that globalization has been crucial in the last several years. Namely, it is a wellknown fact that globalization is not a sudden occurrence or event - it is a phenomenon that implies a correlation between economic, social, political, cultural and ecological processes which continuously shape and reshape the world. Globalization is also an asymmetrical process since, geographically speaking, it does not occur on an even scale, which is why, among other things, this asymmetry is perceived as having a larger influence on urban than on rural spaces (Mc Grew, 2005). To some groups of subjects this process has brought homogenization, to others - variety and heterogeneity. For some, this global occurence has reduced the capacity of the individual, family or community to shape their own lives, while for others it has opened a possibility of developing the very same capacities.

However, in recent human history, not only globalization and similar factors, but also other processes such as industrialization, technological revolution and modernization, have influenced urban transformation. Migrations have been a constant factor in mankind's history. The question is how this factor operates in the circumstances of globalization, modernization or technological revolution,and what is the adequate response when migrations and waves of refugees colonize cities and urban spaces, disrupt social cohesion, cause negative reactions of the local population, and affect policies adopted in this domain at all levels, etc. Taking the foregoing into account, in this paper we will view and analyse urban transformation from the perspective of two concepts: new urbanism and security culture. Namely, both concepts apply cultural analysis, which seeks to promote the knowledge of how certain
\end{abstract}


structural changes affect the social environment, social and cultural life of a city and especially the growing social polarization and segregation. Here, too, we will emphasize the significance of societal culture, which is employed not only as a means to understand the actual changes, but is used,just as frequently as a tool for producing changes, which is recognizable in both of the afore-mentioned concepts.

New Urbanism is a paradigm that has been on the rise in recent decades, and it represents the main frame of reference for considering social and cultural aspects in urban planning as well as integrating approaches from the field of urban planning with those from the arts and humanities. In urban planning studies, cultural factors have been taken into account mainly in the observance of regulations concerning respect for historical sites and protection of cultural goods. The practice of urban planning and research should additionally consider cultural aspects relevant to security and accomplish mutual understanding. It is well known that New Urbanism is devoted to reconciling physical infrastructure and community building and that it follows some sort of physical determinism. This concept suggests that informed, progressive architectural design in itself shapes and improves human behaviour, reduces insecurity and its attendant feelings and, by extension, enhances social resilience.

There are a number of reasons why it is important also to apply the concept of security culture in urban planning in order for the process of transformation to be realized as painlessly as possible. Namely, culture determines human behaviour and perception and defines what constitutes subjective security; in addition, the framework of urbanism is, to a certain extent, culture-defined; finally, cultural behaviour is oriented towards the environment, that is to say, it is the result of urban planning (Siedschlag et al., 2012). Like New Urbanism, security culture uses the approach to security in the community. It implies a shift in the development of infrastructure, political and public understanding of security, from situational prevention to community security as a whole. It also requires a special sensibility for multicultural planning in milieus where that multiculturality is already expressed or in surroundings where there is a possibility for multiculturality to develop, which can be a result of recent migratory currents and the migrants' settling of or temporary residence in urban/city space (Baum, 2000).

Keywords: urban transformation, new urbanism, security culture, migration 